\title{
ANÁLISE DE CRESCIMENTO DE UMA CULTURA DE MILHO SUBMETIDA A DIFERENTES REGIMES HÍDRICOS
}

\author{
GARCIA, Anice ${ }^{1}$ \\ ANDRÉ, Romísio Geraldo Bouhid ${ }^{2}$ \\ GALBIATTI, João Antônio ${ }^{3}$ \\ TANNOUS, Simone ${ }^{4}$
}

\begin{abstract}
RESUMO: O objetivo deste trabalho foi avaliar, através da análise de crescimento, os efeitos de três regimes hídricos sobre o desenvolvimento da cultura de milho. O experimento foi conduzido no ano de 1993, na Área Demonstrativa e Experimental de irrigação da Faculdade de Ciências Agrárias e Veterinárias de Jaboticabal (UNESP). O delineamento experimental foi inteiramente casualizados, com três tratamentos e 4 repetições. Os tratamentos consistiram em três períodos de irrigação:T1: durante todo o ciclo; T2: após a emissão da $12^{\mathrm{a}}$ folha e T3: até 20 dias após o florescimento. Para avaliação da área foliar e da produção de matéria seca total (MST), foram coletadas seis plantas por parcela, em cinco avaliações. Foram avaliados também: o índice de área foliar, a taxa de crescimento da cultura, a taxa de crescimento relativo, taxa assimilatória líquida e a razão de área foliar. A análise de crescimento evidenciou que a deficiência hídrica afeta negativamente os índices fisiológicos do crescimento da cultura do milho e que a deficiência durante o período vegetativo (após a emissão da $12^{\mathrm{a}}$ folha) foi a que mais afetou a cultura em termos fisiológicos e de produção.
\end{abstract}

Palavras-chave: Deficiência hídrica. Parâmetros fisiológicos. Zea mays.

\section{GROWTH ANALYSIS OF MAIZE IN RESPONSE TO DIFFERENT WATER LEVELS}

SUMMARY: The objective of this work was to evaluate, through the growth analysis, the effects of three water systems on maize culture development. The experiment was conducted in 1993, at the experimental area of the Rural Department of Faculdade de Ciencias Agrárias e Veterinárias de Jaboticabal, São Paulo state, Brazil. The experimental design used was a complete randomized block design, with three treatments and four replications. The treatments consisted at three irrigation periods (all time; after the emission of the $12^{\text {th }}$ leaf and 20 days after flowering time). For evaluation of the foliar area and of the production of total dry matter (MST), six plants were collected by portion, being these picked at random, in five evaluations. Were also analyzed: crop growth rate, relative growth rate, leaf area ratio, the net assimilation rate. The growth analysis evidenced that the water deficiency affects the physiologic indexes of the growth negatively in the maize crop and that the deficiency during the vegetative period (after the emission of the $12^{\text {nd }}$ leaf) was that moretaffected the crop in physiologic terms and production.

Keywords: Water stress. Physiological parameters. Zea mays.

\section{INTRODUÇÃO}

A influência dos elementos do microlima (radiação, temperatura, vento e umidade) sobre as características morfológicas de um dossel de cultura e sobre a eficiência de processos 1 Prof. ${ }^{\text {a }}$ FE/FAFRAM

2 Prof. UENF-LENEP. E-mail. romisio@lenep uenf br

3 Prof. UNESP - Dpto. Engenharia Rural

4 Engenheira Agrônoma 
fisiológicos, definem a quantidade de fotoassimilados que uma planta produz. Quando esse microclima é alterado, através do déficit hídrico, por exemplo, as plantas têm o seu comportamento alterado (temperatura foliar, redução na absorção de $\mathrm{CO}_{2}$, resistência aerodinâmica, resistência da cultura à evaporação, etc), o que acabará afetando os fotoassimilados e, portanto, o crescimento e desenvolvimento da cultura (GARCIA et al., 2000; GARCIA; ANDRE, 2001; ROMANO, 2005).

O termo "análise de crescimento" se refere a um série de métodos quantitativos que descrevem e interpretam o desempenho de uma planta, crescendo sob condições naturais, ou controladas, dando uma aproximação explicativa, holística e integral para interpretar as formas e funções da planta (HUNT, 2003). Pereira; Machado (1987) consideram a análise de crescimento como método-padrão para se medir a produtividade biológica de uma cultura, permitindo o estudo de diferentes cultivares de uma determinada cultura em seu ambiente de produção, requerendo informações que podem ser obtidas sem a necessidade de equipamentos sofisticados. Tais informações são a quantidade de material contido na planta toda e em suas partes (folhas, colmos, raízes e frutos), e o tamanho do aparelho fotossintetizante (área foliar), obtidas a intervalos de tempo regulares durante o desenvolvimento fenológico da planta.

O objetivo deste trabalho foi avaliar, através da análise de crescimento, os efeitos de três regimes hídricos sobre o desenvolvimento da cultura de milho.

\section{MATERIAL E MÉTODOS}

O trabalho foi desenvolvido de maio a agosto de 1993, na Área Demonstrativa e Experimental de irrigação-ADEI, do Departamento de Engenharia Rural, da Faculdade de Ciências Agrárias e Veterinárias (FCAV/UNESP), Campus de Jaboticabal, (2115'22”S, 48¹8'58'W, 595 metros); com superfície do solo com exposição norte e declividade média de 10\%. O solo é um Latossol roxo, classificado como grande grupo, Jaboticabal ao nível de série, ordem Oxisol, sub ordem Orthox, grande grupo Eutrorthox e sub grupo typic Eutrortox.

O híbrido de milho (Zea mays L.) avaliado foi o Dina-70, que é um híbrido duplo desenvolvido pela Dinamilho/CAROL e que apresenta início de florescimento por volta dos 63 dias após emergência, altura média da planta de 2,60 metros e grãos cor laranja, tipo semiduro. Indicado para semeadura em época normal e para safrinha. A emergência de 50\% das plantas se deu no dia 02/05. A ocorrência dos estádios no tempo, em relação à emergência foram: 12 folhas: 42 dias após a emergência (DAE); florescimento: 60 DAE; ponto de maturidade fisiológico: 127 DAE.

O delineamento experimental foi inteiramente casualizado com 3 tratamentos e 4 repetições: T1 = irrigação durante todo o ciclo; T2= irrigação a partir da $12^{\mathrm{a}}$ folha; $\mathrm{T} 3=$ irrigação até 20 dias após florescimento.

A irrigação foi realizada por aspersão, com base na evaporação do Tanque Classe A, aplicando-se o coeficiente de uso consuntivo $\left(\mathrm{K}_{\mathrm{c}}\right)$ do milho (DOORENBOS; PRUITT, 1984). 
Foram utilizados aspersores do tipo ZE-30D, da Asbrasil, com bocais de 4,5 x 5,5 mm de diâmetro, em um espaçamento de 18 x 18 metros, operados com três atmosferas de pressão de serviço, aplicando precipitação de $10 \mathrm{~mm} /$ hora. A aplicação de adubo, por ocasião da semeadura, para todo o experimento, foi feita com base na análise do solo e na dosagem correspondente a $150 \mathrm{~kg} / \mathrm{ha}$ da fórmula de 4-20-20. A semeadura foi efetuada em final de abril, manualmente, usando-se 15 sementes por metro linear, e o desbaste, aos 25 dias após a semeadura, mantendose quatro plantas por metro linear. Um mês após a semeadura, aplicou-se, manualmente, 100 $\mathrm{kg} / \mathrm{ha}$ de uréia em cobertura, ao lado de cada linha de milho.

Para determinar o potencial matricial da água no solo, foram usados tensiômetros de coluna de mercúrio $(\mathrm{Hg})$, instalados dois em cada parcela experimental, nas profundidades de $30 \mathrm{~cm}$. O objetivo da determinação do potencial matricial da água no solo foi verificar as tensões de água no solo, nos diferentes níveis de irrigação aplicados.

A observação dos parâmetros fisiológicos das plantas (acúmulo de matéria seca e área foliar) foi realizada segundo metodologia proposta por Carleton; Foote (1975), de seis plantas por parcela, sendo estas colhidas ao acaso, em cinco avaliações, devidamente espaçadas para abranger cada uma das fases da cultura a saber: três durante o período vegetativo (aos 23, 39 e 51 DAE), uma durante o florescimento (aos $67 \mathrm{DAE}$ ), e a última durante o período de enchimento de grãos (aos 107 DAE).

A partir da AF e da MS e através do programa ANACRES (PORTES; CASTRO JR, 1991) foram calculados os seguintes parâmetros fisiológicos: a) índice de área foliar (IAF), determinado pela relação entre a AF média de uma planta, em $\mathrm{m}^{2}$, e a superfície correspondente de terreno, sendo as curvas ajustadas, em função do tempo, por uma equação exponencial quadrática; b) taxa de crescimento da cultura (TCC), determinada por meio da derivada da equação ajustada da matéria seca total em relação ao tempo, em $\mathrm{g} \mathrm{m}^{-2} \mathrm{dia}^{-1}$; c) taxa de crescimento relativo (TCR), expressa em $\mathrm{g} \mathrm{g}^{-1} \mathrm{dia}^{-1}$ e calculada pelo quociente entre a TCC e a MS; d) taxa assimilatória líquida (TAL), determinada pela razão entre a TCC e o IAF, em $\mathrm{g} \mathrm{m}^{-2} \mathrm{dia}^{-1}$; e) razão de área foliar (RAF), definida como sendo o quociente entre a AF e a MS. Para os parâmetros fisiológicos, calculados na análise de crescimento, não foram feitas as análises de variância, pois, sendo variáveis calculadas, não é possível afirmar que as mesmas obedeçam às pressuposições básicas para esse tipo de análise (BANZATTO; KRONKA, 1989).

Os parâmetros de produção da cultura $\left(\mathrm{kg}\right.$. espiga $\left.\mathrm{a}^{-1} \mathrm{e} \mathrm{kg.ha-1}\right)$ foram obtidos, colhendo-se todas as plantas de duas linhas centrais de cada parcela.

\section{RESULTADOS E DISCUSSÃO}

O estresse a que foram submetidos os tratamentos T2 e T3 podem ser percebidos pela evolução da tensão de água no solo, medido através de tensiômetros (Figura 1). 


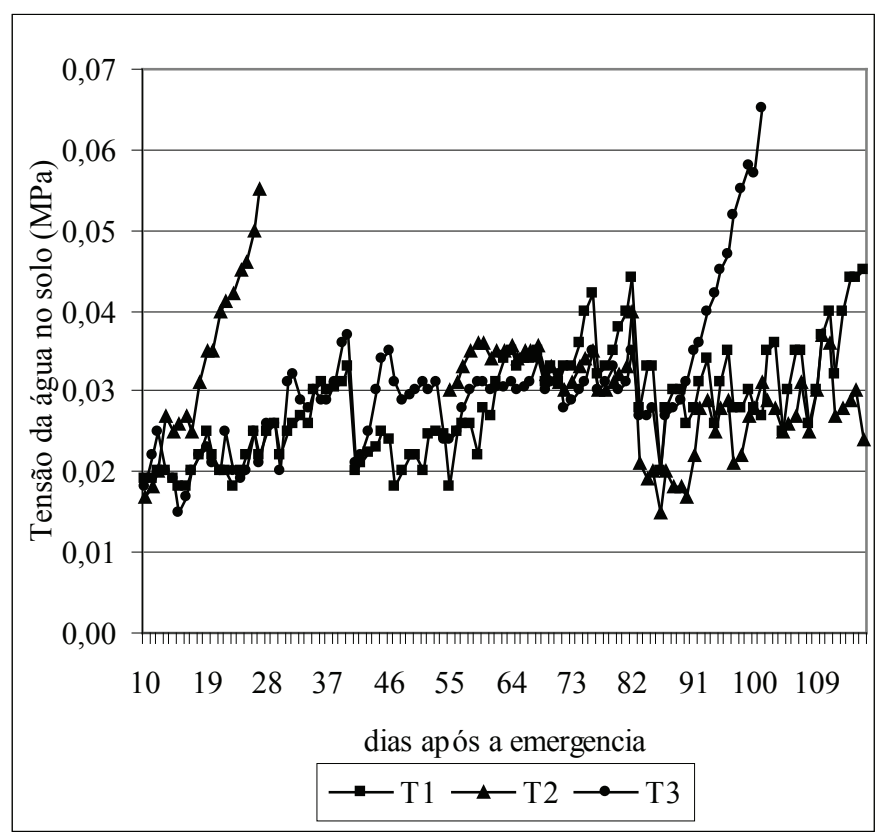

Figura 1: Tensão média da água no solo, para os diferentes tratamentos, na cultura de milho.

Nota-se que, no tratamento T2, a tensão de água no solo aumentou até 27 DAE, quando se precisou desativar os tensiômetros, sendo reativados em $42 \mathrm{DAE}$, época da emissão da $12^{\mathrm{a}}$ folha, quando este tratamento passou a ser irrigado. O tratamento T3 deixou de ser irrigado 20 dias após o florescimento (80 DAE), e, portanto, a tensão de água no solo passou a aumentar, sendo os tensiômetros desativados em 101 DAE. No restante do período, os tratamentos se mantiveram em torno de $0,03 \mathrm{MPa}$, valor considerado como próximo à capacidade de campo.

A matéria seca total (MS) (Tabela 1) apresentou diferença significativa entre os regimes de irrigação somente aos 107 DAE, em que as plantas submetidas ao déficit, seja inicial ou após o florescimento, apresentaram menor acúmulo de MS. A Figura 2 apresenta as curvas ajustadas da MS em função do tempo $(\mathrm{R}=0,98$ e 0,99$)$, para os 3 tratamentos, verificando-se que o acúmulo de matéria seca do milho foi influenciado pelo regime de irrigação. Até os 39 DAE, as diferenças na produção de matéria seca foram praticamente inexistentes. A partir dos $51 \mathrm{DAE}$, o tratamento T2, que só passou a ser irrigado após a emissão da $12^{\mathrm{a}}$ folha, apresentou o menor acúmulo de matéria seca. O tratamento T3, que deixou de ser irrigado 20 dias após o florescimento, apresentou o menor acúmulo de matéria seca total na ultima avaliação, mas isso não afetou a produção, como se verá adiante.

Tabela 1: Produção de matéria seca total $\left(\mathrm{g} \cdot \mathrm{cm}^{-2}\right)$ em cada uma das coletas, para os diferentes tratamentos, na cultura de milho.

\begin{tabular}{llllll}
\hline \multirow{2}{*}{ Tratamento } & \multicolumn{5}{c}{ Dias após a emergência (DAE) } \\
\cline { 2 - 6 } & 23 & 39 & 51 & 67 & 107 \\
\hline T1 & $1,08 \mathrm{a}^{*}$ & $5,75 \mathrm{a}$ & $60,75 \mathrm{a}$ & $128,56 \mathrm{a}$ & $291,00 \mathrm{a}$ \\
T2 & $0,62 \mathrm{a}$ & $2,66 \mathrm{a}$ & $36,63 \mathrm{a}$ & $120,07 \mathrm{a}$ & $238,05 \mathrm{~b}$ \\
T3 & $1,10 \mathrm{a}$ & $7,38 \mathrm{a}$ & $50,61 \mathrm{a}$ & $129,44 \mathrm{a}$ & $229,92 \mathrm{~b}$ \\
\hline
\end{tabular}

*Médias seguidas de mesma letras na coluna, não diferem entre si pelo teste de Tukey 


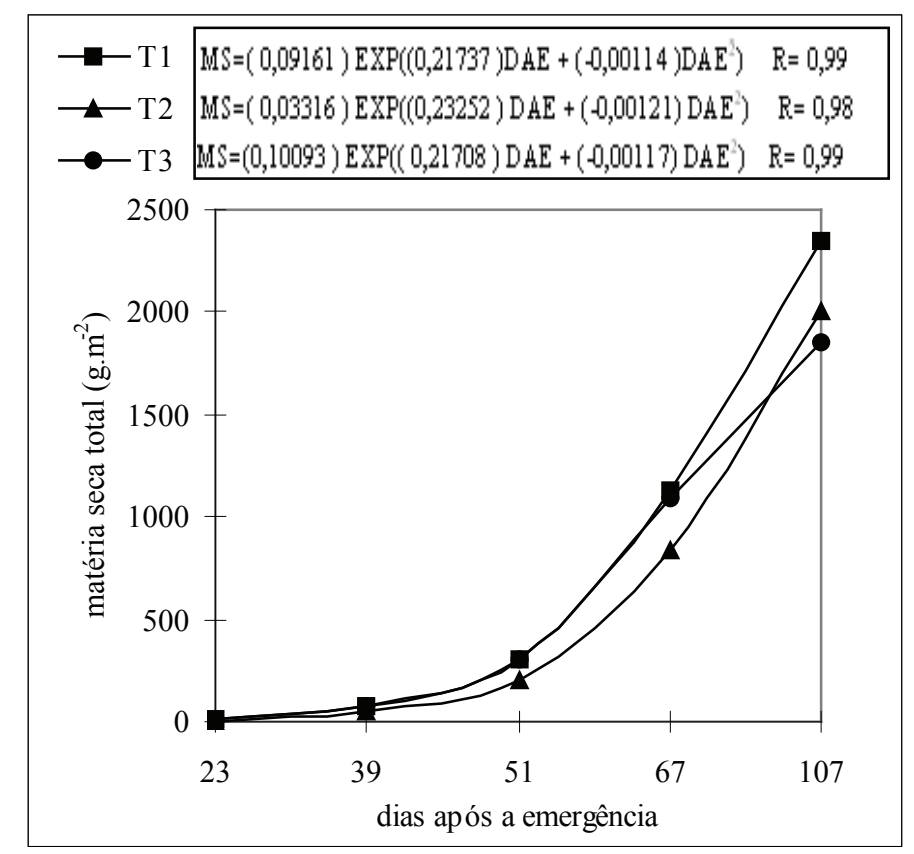

Figura 2: Produção de matéria seca total de milho em cada uma das coletas, para os diferentes tratamentos, na cultura de milho.

O índice de área foliar (IAF) apresentou diferença significativa entre os diferentes tratamentos a partir da terceira avaliação, sendo que o tratamento T2 foi o que apresentou os menores valores do índice (Tabela 2).

Tabela 2: Índice de área foliar em cada uma das coletas, para os diferentes tratamentos, na cultura de milho.

\begin{tabular}{cccccc}
\hline \multirow{2}{*}{ Tratamento } & \multicolumn{5}{c}{ Dias após a emergência (DAE) } \\
\cline { 2 - 6 } & 23 & 39 & 51 & 67 & 107 \\
\hline T1 & $0,21 \mathrm{a}^{*}$ & $0,82 \mathrm{a}$ & $4,18 \mathrm{a}$ & $4,24 \mathrm{a}$ & $4,55 \mathrm{a}$ \\
T2 & $0,11 \mathrm{a}$ & $0,48 \mathrm{a}$ & $3,16 \mathrm{~b}$ & $3,74 \mathrm{~b}$ & $3,60 \mathrm{~b}$ \\
T3 & $0,17 \mathrm{a}$ & $0,97 \mathrm{a}$ & $3,63 \mathrm{ab}$ & $3,88 \mathrm{ab}$ & $4,05 \mathrm{ab}$ \\
\hline
\end{tabular}

*Médias seguidas de mesma letras na coluna, não diferem entre si pelo teste de Tukey

A Figura 3 evidencia as curvas ajustadas do IAF em função do tempo $(\mathrm{R}=0,98)$. $\mathrm{O}$ tratamento T2 foi o que apresentou menor IAF em todas as avaliações, intensificando-se ainda mais, durante o período reprodutivo da cultura. Entre o tratamento T1 e T2, praticamente, não houve diferenças em relação ao IAF, a não ser na ultima avaliação. 


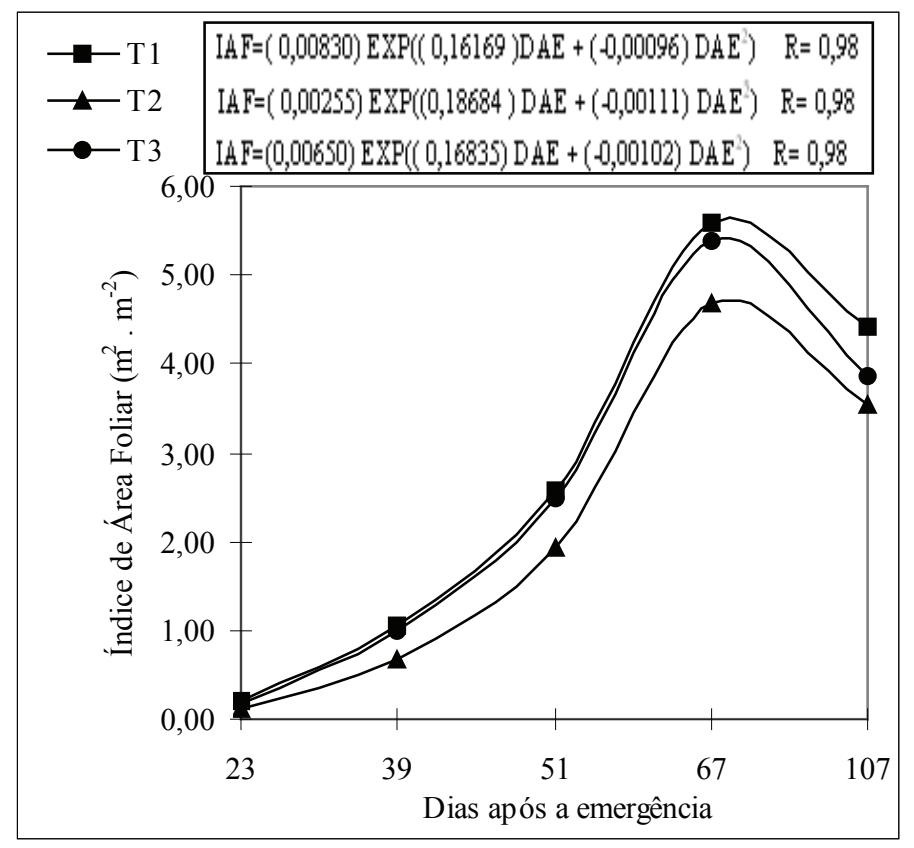

Figura 3: Índice de Área foliar em cada uma das coletas, para os diferentes tratamentos, na cultura de milho.

O IAF máximo, obtido pelas curvas ajustadas em todos os tratamentos, ocorreu em torno dos 67 DAE, no estádio de florescimento, sendo de 5,58, 4,69 e 5,39 respectivamente, nos tratamentos T1, T2 e T3. Soler (2004) também encontrou valores máximos de IAF para milho durante o período de florescimento, variando entre 2,5 e 5,0, dependendo do hibrido. O IAF crítico para a cultura do milho encontra-se dentro dos limites de 3 a 5 , observados por (BOEDHRAM et al., 2001) e (SÁ et al., 2002).

As curvas ajustadas do IAF e seus respectivos valores máximos confirmam que o milho teve melhor desenvolvimento no T1, que possibilitou maior expansão e menor abscisão das folhas, implicando elevação do IAF.

A taxa de crescimento da cultura (TCC) (Figura 4) pode ser usada para se ter idéia da velocidade média de crescimento ao longo do período de observação.

As curvas da taxa de crescimento da cultura (TCC) em função do tempo, para os diferentes tratamentos, evidenciam menor acúmulo e produção de matéria seca de plantas de milho no tratamento T2, o que concorda com os resultados obtidos de matéria seca total e área foliar. 


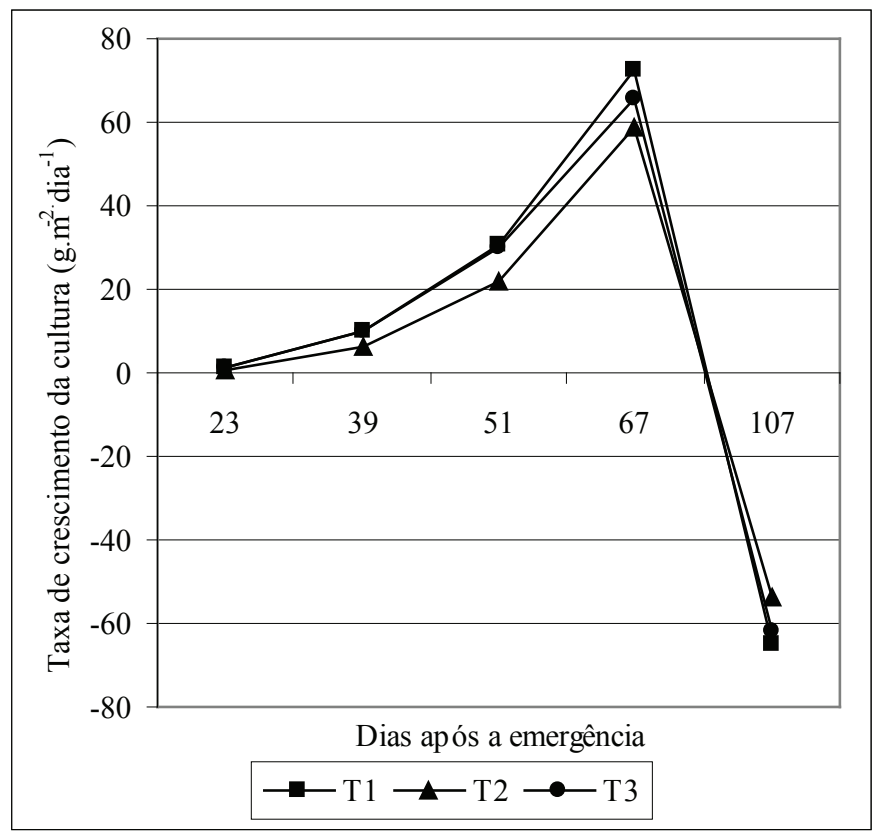

Figura 4: Taxa de crescimento da cultura, de plantas de milho em cada uma das coletas, para os diferentes tratamentos.

As curvas da taxa de crescimento relativo (TCR), em razão dos DAE da cultura do milho, submetidas a diferentes épocas de supressão de irrigação são mostradas na Figura 5. A TCR reflete o aumento da matéria orgânica seca, em gramas, das plantas, num período de tempo, sendo função do tamanho inicial, ou seja, do material pré-existente.

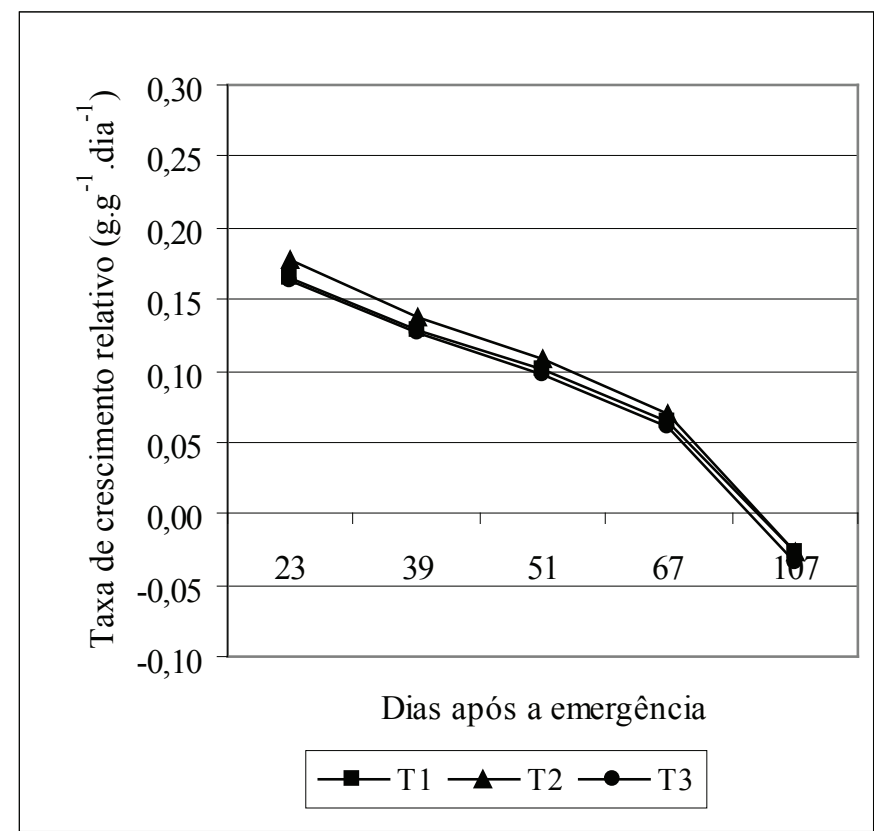

Figura 5: Taxa de crescimento relativo de plantas de milho em cada uma das coletas, para os diferentes tratamentos.

Os três tratamentos, praticamente, não apresentaram diferenças quanto a este índice 
fisiológico.

O comportamento decrescente dessa variável a cada nova fase do ciclo da cultura, bem como suas magnitudes estão de acordo com os observados para milho por Romano (2005) e por Lopes (1973) que foi de, aproximadamente, 0,25 $\mathrm{g} \mathrm{g}^{-1} \mathrm{dia}^{-1}$. Entre o $25^{\circ}$ e o $30^{\circ}$ dia após emergência, atingindo, aos 40 DAE, valores de aproximadamente $0,10 \mathrm{~g} \mathrm{~g}^{-1} \mathrm{dia}^{-1}$, reduzindo lentamente, após este período.

Em relação ao tempo, verifica-se que a tendência geral de TCR é a redução com o desenvolvimento do ciclo da cultura. Assim, percebe-se uma fase inicial de rápido acúmulo de material, seguida de uma com menor incremento. Esse comportamento de TCR é amplamente reportado na literatura, como em Aguiar Neto et al. (2000); Benincasa (1988), Rodrigues (1990) e Moreira; Rodrigues (1995), e pode ser explicada pelo aumento da competição intraespecífica, pelos principais fatores ambientais responsáveis pelo crescimento, tais como água, luz, nutrientes e difusão de $\mathrm{CO}_{2}$, dentro do "stand", entre outros (GAVA et al., 2001). O declínio dessa taxa de crescimento, portanto, é esperado, conforme a planta vai atingindo a maturidade, devido ao aumento gradual de tecidos não assimilatórios.

A taxa assimilatória líquida é um parâmetro de crescimento que representa o incremento de fitomassa por unidade de área foliar durante um determinado tempo, normalmente, um dia. Ela difere da taxa fotossintética líquida por computar todo o balanço de um dia, e não apenas do período luminoso.

Na Figura 6, apresentam-se os valores relativos à TAL calculados para o período do experimento. Nota-se que houve um aumento da TAL para os três tratamentos até a avaliação de 67 DAE, e, na ultima avaliação, uma redução brusca, o que se explica pelos decréscimos subseqüentes com o desenvolvimento fenológico da cultura, decorrentes do surgimento de tecidos e estruturas não assimilatórias, vagens e sementes, além do auto-sombreamento, secamento e queda de folhas com a idade da planta. Esse comportamento da TAL também foi observado por Lopes et al. (1982), Urchei (1992). Porém entre os tratamentos, praticamente, não se observou diferença da TAL.

Nucleus, v. 5. n. 1 , abr. 2008 


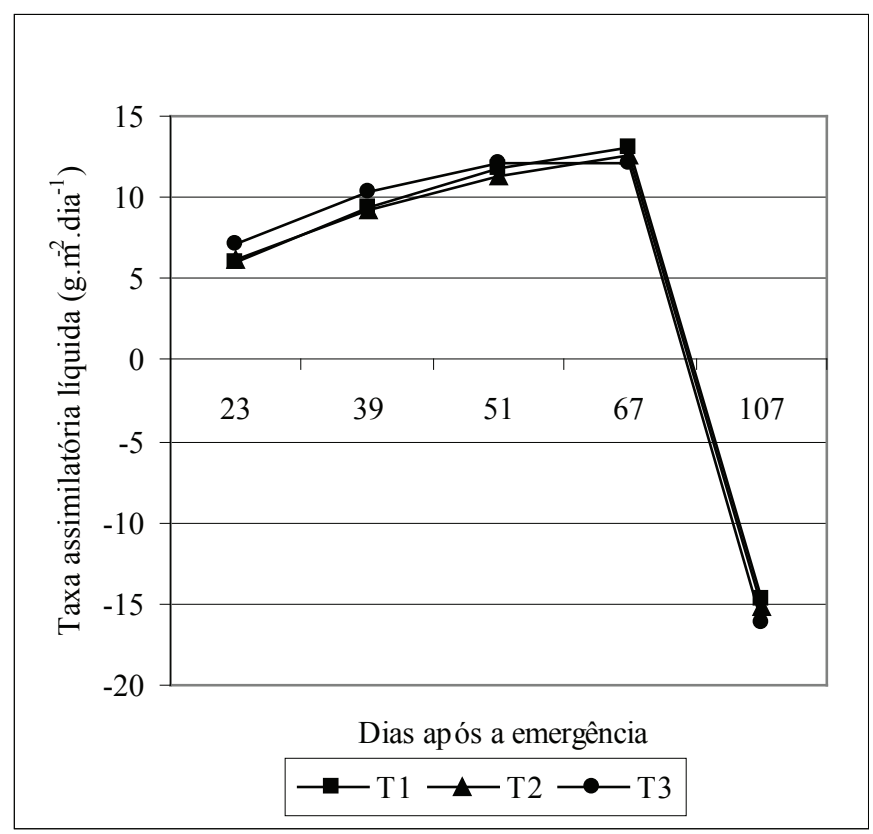

Figura 6: Taxa assimilatória líquida, para plantas de milho em cada uma das coletas, para os diferentes tratamentos.

A razão de área foliar (RAF) (Figura 7) é um componente morfofisiológico do crescimento, pois expressa a razão entre a área foliar (responsável pela interceptação luminosa) e a massa seca total (resultado da fotossíntese) e representa a área foliar usada pela planta para produzir uma unidade de massa seca (BENINCASA, 1988).

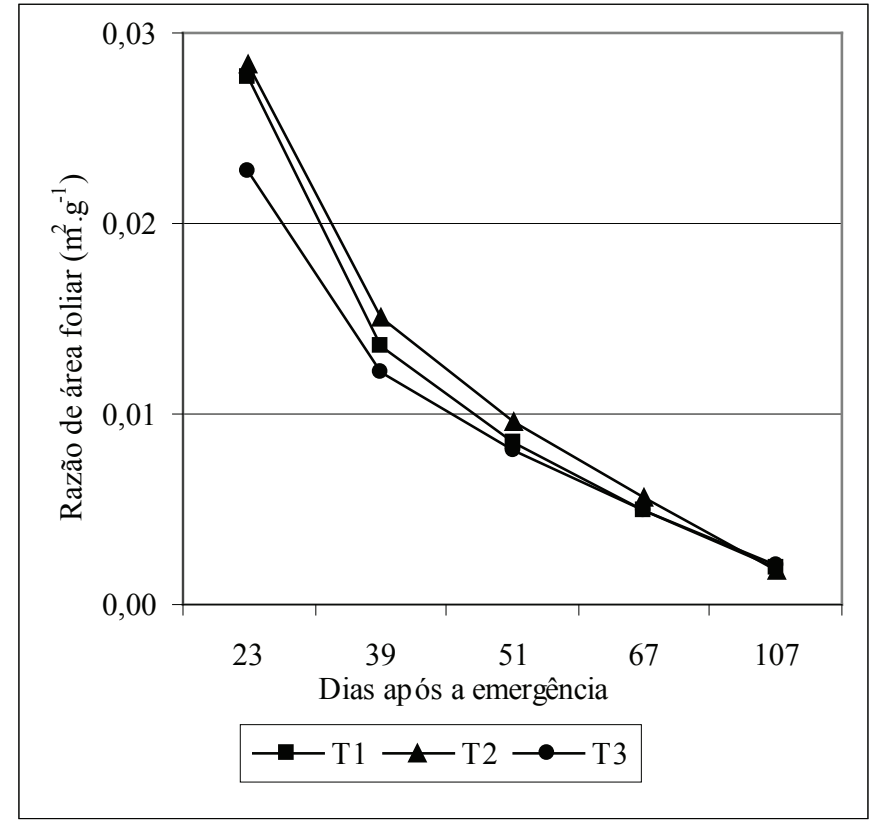

Figura 7: Razão de área foliar para plantas de milho em cada uma das coletas, para os diferentes tratamentos

De um modo geral, a razão de área foliar, que é a área foliar útil para a fotossíntese, 
decresce com o desenvolvimento das plantas de milho, coincidindo com o relatado por Koller et al. (1970); Lopes et al. (1982); Urchei (1992). Isto se justifica, possivelmente, por causa do sombreamento de folhas superiores em folhas inferiores, diminuindo, assim, a taxa fotossintética, além do surgimento de tecidos e estruturas que são drenos altamente competitivos (órgãos reprodutivos).

É interessante notar que, apesar de apresentar menor acúmulo de matéria seca e menor área foliar, o tratamento T2 apresentou uma maior RAF que os demais, talvez como estimulo da planta sob déficit em converter a maior parte dos assimilados em folhas, visando a elevar a captação da radiação solar. Isto concorda com o trabalho de Vilela; Bull (1999) que observaram menores valores de RAF em plantas de milho, nos tratamentos em que a disponibilidade hídrica foi maior. Além disso, levando-se em conta que esse índice diminui por causa do autosombreamento, como o explicado acima, pode-se inferir que, neste tratamento, por causa do estresse, as folhas estavam menos túrgidas, provocando um movimento de para-heliotropismo nas folhas superiores, permitindo uma melhor penetração da radiação solar dentro da cultura o que pode ter contribuído para aumentar a eficiência fotossintética. Esse posicionamento de folhas mais ou menos paralelamente aos raios solares, como defesa para redução de perda d'água, também foi observado em plantação de feijão sob estresse hídrico por Garcia (2000). Entretanto, isso não se refletiu na produção da cultura (Tabela 3).

Tabela 3: Valores médios de produção de grãos para os diferentes tratamentos, na cultura de milho.

\begin{tabular}{ccc}
\hline \multirow{2}{*}{ Tratamento } & \multicolumn{2}{c}{ Produção } \\
\cline { 2 - 3 } & Kg.espiga $^{-1}$ & Kg.ha $^{-1}$ \\
\hline T1 & $0,13 \mathrm{a}$ & $5.399 \mathrm{a}$ \\
T2 & $0,09 \mathrm{~b}$ & $3.914 \mathrm{~b}$ \\
T3 & $0,10 \mathrm{ab}$ & $5.001 \mathrm{ab}$ \\
\hline
\end{tabular}

Pode-se observar que a maior produção foi obtida quando as plantas não foram submetidas ao déficit hídrico (T1), mas este não diferiu significativamente do tratamento T3, em que as plantas deixaram de receber irrigação 20 dias após o florescimento, indicando que, nesta fase, há uma diminuição da necessidade hídrica da cultura. O tratamento T2, em que as plantas só receberam irrigação após a emissão da $12^{\mathrm{a}}$ folha, foi o que apresentou menor produção, refletindo o que aconteceu com a maioria dos índices fisiológicos estudados, o que se explica pelo fato de que o período entre o estádio de 12 folhas e o florescimento é marcado pelo desenvolvimento das estruturas reprodutivas do milho, e o número potencial de grãos por espiga é determinado quando as plantas atingem 10 a 12 folhas com o colar visível (Rodrigues \& Didonet, 2003). O desenvolvimento destas estruturas representa o principal "dreno" para os fotoassimilados produzidos na folha. Neste período, a cultura reduz a taxa de crescimento de cultura (Figura 4). A habilidade de alocar os fotoassimilados das "fontes" (folhas) para os drenos (regiões meristemáticas de desenvolvimento das estruturas reprodutivas) pode ser 
determinante na produtividade final da cultura.

\section{CONCLUSÃO}

A deficiência hídrica afeta negativamente os índices fisiológicos do crescimento na cultura do milho.

A deficiência, durante o período vegetativo (após a emissão da $12^{\mathrm{a}}$ folha), foi a que mais afetou a cultura em termos fisiológicos e de produção.

\section{REFERÊNCIAS}

AGUIAR NETTO, A.O. Comportamento fisiológico e produtivo da ervilha (Pisum sativum - L.), submetida a diferentes potenciais água no solo. Botucatu: UNESP, 1993. 149p. Dissertação (Mestrado).

BANZATTO, D.A.; KRONKA, S.N. Experimentação Agrícola. Jaboticabal: FUNEP, 1989. $247 \mathrm{p}$.

BENINCASA, M.M.P. Análise de crescimento de plantas: noções básicas. Jaboticabal: FUNEP, 1988. 42p.

BOEDHRAM, N.; ARKEBAUER, T.J.; BATCHELOR, W.D. Season-long characterization of vertical distribution of leaf area in corn. Agron. J., v.93, p.1235-42, 2001.

CARLETON, A.E.; FOOTE, W.H. A comparison of methods for estimating total leaf area of barley plants. Crop Science, Madison, v.5, p.603, 1975.

DOORENBOS, J.; PRUITT, W.O. Crop water requirements. Rome: FAO, 1984. 144p. (FAO. Irrigation and Drainage Paper, 24).

GARCIA A.; ANDRÉ, R.G.B. Efeito do déficit hídrico sobre as características fenológicas de uma cultura de feijão. In: Congresso Brasileiro de Agrometeorologia, 12, 2001. Anais... Fortaleza: Sociedade Brasileira de Agrometeorologia, 2001. p. 451-2.

GARCIA, A. Utilização da temperatura do dossel, na estimativa de índices de estresse hídrico para o feijoeiro (Phaseolus vulgaris L.). Jaboticabal: UNESP, 2000. 134p. Tese (Doutorado).

GARCIA, A. et al. Diurnal and seasonal variations of CWSI and non-water-stressed baseline with nectarine trees. Acta Horticulturae, v.537, p. 415-421, 2000.

GAVA, G.J.C. et al. Crescimento e acúmulo de nitrogênio em cana-de-açúcar cultivada em solo coberto com palhada. Pesquisa Agropecuária Brasileira, Brasília, v.36, n.11, p.1347-1354, 
2001.

HUNT, R. Growth analysis, individual plants. In: THOMAS B, MURPHY D.J.; MURRAY D. (eds.) Encyclopaedia of Applied Plant Sciences. London: Academic Press. p.579-588, 2003.

KOLLER, H.R.; NYQUIST, W.E.; CHORUSH, I.S. Growth analysis of the soybean community. Crop Science, Madison, v.10, p.407-11, 1970.

LOPES, N.F. Análise de crescimento e conversão da energia solar em população de milho (Zea mays L.) em Viçosa, Minas Gerais. Viçosa: UFV, 1973. 61p. Dissertação (Mestrado).

LOPES, N.F. et al. Análise de crescimento e conversão da energia solar em feijoeiro (Phaseolus vulgaris L.) submetido a três níveis de densidade do fluxo radiante. Revista Ceres, Viçosa, v.29, n.166, p.586-606, 1982.

MOREIRA, J.A.A.; RODRIGUES, J.D. Efeitos da tensão da água do solo e do parcelamento da adubação nitrogenada sobre o crescimento e a produtividade do feijao vagem.. In: Congresso Brasileiro de Ciência do Solo, 1995, Viçosa. Resumos.... Viçosa: SBCS, 1995. v.3, p.17431745.

PEREIRA, A.R.; MACHADO, E.C. Análise quantitativa do crescimento de comunidades vegetais. Campinas : IAC, 1987. 33p. (IAC. Boletim Técnico, 114).

PORTES, T.A.; CASTRO JR., L.G. Análise de crescimento de plantas: um programa computacional auxiliar. Revista Brasileira de Fisiologia Vegetal. Campinas, v.3, n.1, p.53-56, 1991.

RODRIGUES, J.D. Influência de diferentes níveis de cálcio, sobre o desenvolvimento de plantas de estilosantes (Stylosanthes guyanensis (Aubl.) Sw. cv. Cook), em cultivo hidropônico. Botucatu : UNESP-FCA, 1990. 180p. Tese (Livre Docência).

RODRIGUES, O.; DIDONET, A.D. Milho: efeito da temperatura na duração e na taxa de crescimento de grãos. S.L: Embrapa-trigo, 2003. (Boletim de pesquisa e desenvolvimento, n.15).

ROMANO, M.R. Desempenho fisiológico da cultura de milho com plantas de arquitetura contrastante: parâmetros para modelos de crescimento. Piracicaba: USP, 2005. 100p. Tese (Doutorado).

SÁ, M.; RAMALHO, M.A.P.; SOBRINHO, F.S. Aspectos morfológicos e fisiológicos de cultivares modernos e antigos de milho. Ciênc. Agrotec., v.26, n.5, p.1082-91, 2002.

SOLER, C. T. Uso do modelo CERES-Maize para identificacao de caracteristicas genéticas desejáveis para milho safrinha e determinação de práticas adequadas de manejo em condições de risco climático. Piracicaba: USP, 2000. 86p. Dissertação (Mestrado). 
URCHEI, M.A. Efeitos de défices hídricos, em três estádios fenológicos, da cultura da cevada (Hordeum vulgare L.). Botucatu: UNESP, 1992. 165p. Dissertação (Mestrado).

VILELA, E.F.; BÜLL, L.T. Avaliação do crescimento de plantas de milho em função de doses de potássio e estresse hídrico. Revista Brasileira de Ciência Solo, v.23, p.281-289, 1999. 